\title{
Research on BL Teaching Mode in College English Visual-audio-oral Course Based on POA
}

\author{
Li Naiqian ${ }^{1}$, WuYafei ${ }^{1, *}$

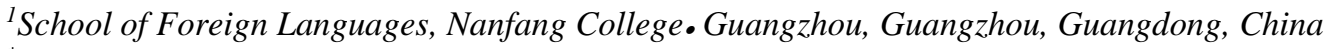 \\ * Corresponding author. Email: wyf888_0@126.com
}

\begin{abstract}
This research is an exploration of applicability of POA and BL in College English Visual-audio-oral Course to testify the effectiveness of this new teaching mode. Forty eight freshmen who major in English from two parallel classes were selected in this study. Two teachers of the two parallel classes conducted a teaching experiment of one unit with the new teaching mode combining POA and BL and traditional teaching methods respectively to compare the teaching effectiveness through teaching data comparison, questionnaire data analysis and teaching logs. The experimental results show that: the combination of POA and BL is superior to traditional teaching methods; However, some difficulties and challenges need to be paid attention to in the effective implementation of POA and BL.
\end{abstract}

Keywords: Production-oriented Approach (POA), Blended Learning (BL), Motivating, Enabling, Assessing

\section{INTRODUCTION}

College English Visual-audio-oral Course is a language practice course that integrates visual, audio and speaking, aiming to improve students' English listening, speaking and language application abilities. But for a long time, this course is basically teacher-centered. Teachers often focus on training students' listening skills by mechanically repeating the single mode of "listening to the text - answer" in class, which leads to a disconnection between listening and speaking. This traditional teaching mode that overemphasizes language input and ignores language output is not suitable for this course, for it affects teaching quality and students' learning enthusiasm. Against "input-driven", Professor Wen Qiufang and her research team put forward the "Product-oriented Approach" (POA), a new theoretical system of foreign language teaching. ${ }^{[1]}$ POA takes "Learning-using Integrated Principle" as the main teaching concept, emphasizing the "output-input-output" teaching sequence and following the teaching process of "motivating-enabling-assessing", which completely overturns the traditional foreign language teaching mode.

Under the background of "Internet Plus", the rapid development of information technology has posed new challenges to education. The Blended Learning (BL) comes into being as online self-learning has become an inevitable learning trend. BL is an "online + offline" learning that combines the advantages of online and traditional learning. The online course platform provides students with learning resources, tasks or assessments before or after class, so as to save classroom teaching time and promote the reconstruction of classroom teaching and truly return the classroom to students.

By the usage of new network media or course aid software, BL is really beneficial for the implementation of POA. In addition, the student-centered teaching philosophy and the leading role of teachers are emphasized in both BL and POA. Therefore, BL is a guarantee for the realization of POA. This article attempts to apply POA and BL to English Visual-audio-oral lessons to improve the language application ability of English majors, examine the teaching effect by conducting one unit of teaching, and explore the advantages and difficulties in the implementation of POA and $\mathrm{BL}$.

\section{OVERVIEW OF POA AND BL}

POA is the exploration and attempt by professor Wen Qiufang and her research team on how to construct a foreign language teaching theory with Chinese 
characteristics. Influenced by Krashen's "Input Hypotheses" [2] and Swain's "Output Hypotheses" [3], POA has been developed over 10 years to overcome the weaknesses in English instruction in tertiary education in China. And POA theoretical system is fully formed in 2015 and further revised in 2017. It consists of three components: teaching principles, teaching hypotheses and teacher-leading teaching process ${ }^{[4]}$, as shown in
Figure 1. Replacing the conventional teaching sequence of "input-output" with the sequence of "output-inputoutput", POA advocates "learning-using integration" and closely combines "input learning" with "productive application" to solve the problem of "separation of learning and application" in the foreign language teaching of our country.

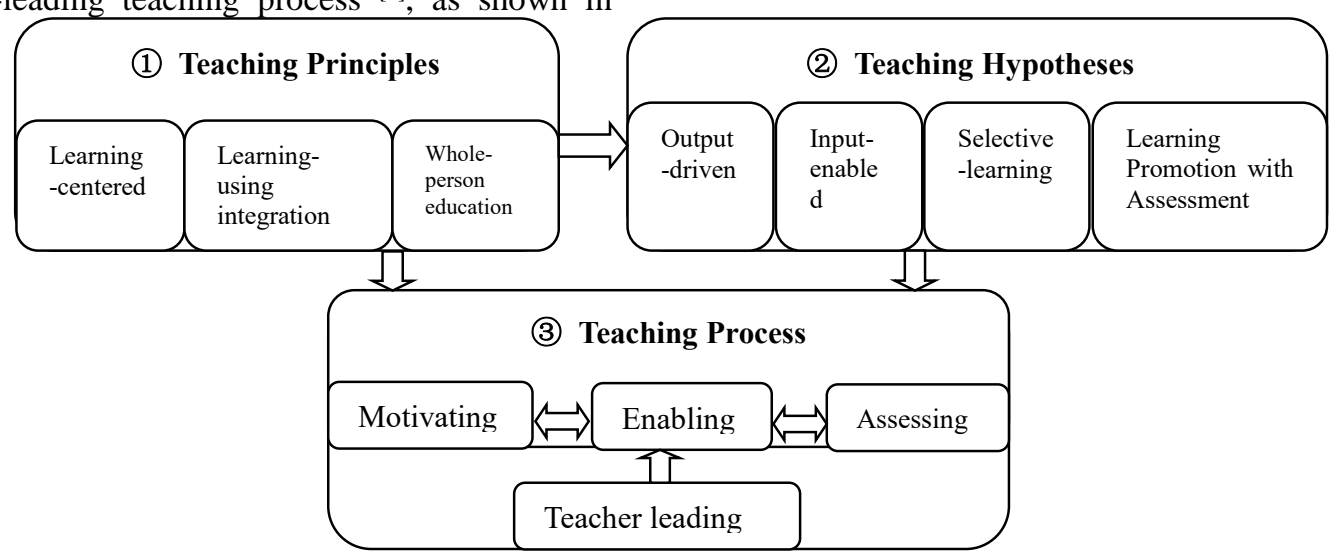

Figure 1: Revised POA theoretical system ${ }^{[5]}$

BL is not a new teaching method or theory, but a learning paradigm that integrates various flexible teaching methods. By the combination of online selfstudy and offline classroom learning, it effectively integrates the advantages of multiple teaching modes, reconstructs traditional classroom teaching in terms of teaching content, teaching methods, teaching organization, and evaluation methods, and emphasizes "the mixture of learning resources, learning environments, learning methods and learning styles". [6] The aim of $\mathrm{BL}$ is to change the traditional pattern of classroom teaching and to solve problems of low learning initiative, insufficient cognitive participation, and differences in learning effects among students because of excessive lecturing. Due to the application of network platform and teaching software, students' learning methods are more diversified, and their learning time and space are also expanded, which is conducive to students' autonomous learning and diversified development. Like POA, BL also stresses the leading role of teachers to achieve the perfect integration of online and offline teaching and learning.

Actually, BL agrees with POA in several aspects and BL provides favorable conditions for the implementation of POA. Therefore, the College English Visual-audiooral course design can be more effective by the combination of the POA teaching theory and the BL learning paradigm.

\section{RESEARCH DESIGN}

\subsection{Brief Introduction}

The subject of the teaching experiment (the experimental group) is a class taught by the author with a total of 24 students. They are freshmen majoring in English in the School of Foreign Languages, NanFang College • Guang Zhou. The control group is a class (a total of 24 students) taught by another teacher using the traditional teaching mode. Since these students just entered the college and students with different English proficiency levels were almost equally distributed in each teaching class, the listening and speaking abilities of the students in the experimental group and the control group before experiment were basically the same.

This experiment is an empirical research with a combination of qualitative and quantitative research methods. For the two classes in this course, the length of teacher's classroom teaching time, the length of students' listening and speaking time, the students' participation rate in classroom and online learning, and the pass rate of output tasks were compared to find out the process and effect discrepancies between the teaching mode combining POA and $\mathrm{BL}$ and the traditional teaching mode. In addition, questionnaires were used to get the information of students' satisfaction degree of the teaching experiment, acceptance degree and the evaluation of POA and BL, and the suggestions of the course etc. With comparative analysis, students' feedback and teachers' reflection in teaching logs, we can find out the superiority of the combination of POA and BL and sum up issues that requires attention in the process of effective implementation. 


\subsection{Teaching Procedure}

The two teachers in the research group adopted the new teaching mode combining POA and BL and traditional teaching mode respectively to teach the experimental group and the control group. The teaching material is derived from Unit 6 "This Way or That Way?" in Listen This Way 1. Their teaching goal is to enable students to ask for and give directions correctly in daily life.

\subsubsection{Teaching procedure in experimental class}

The specific teaching steps are as shown in Figure 2:

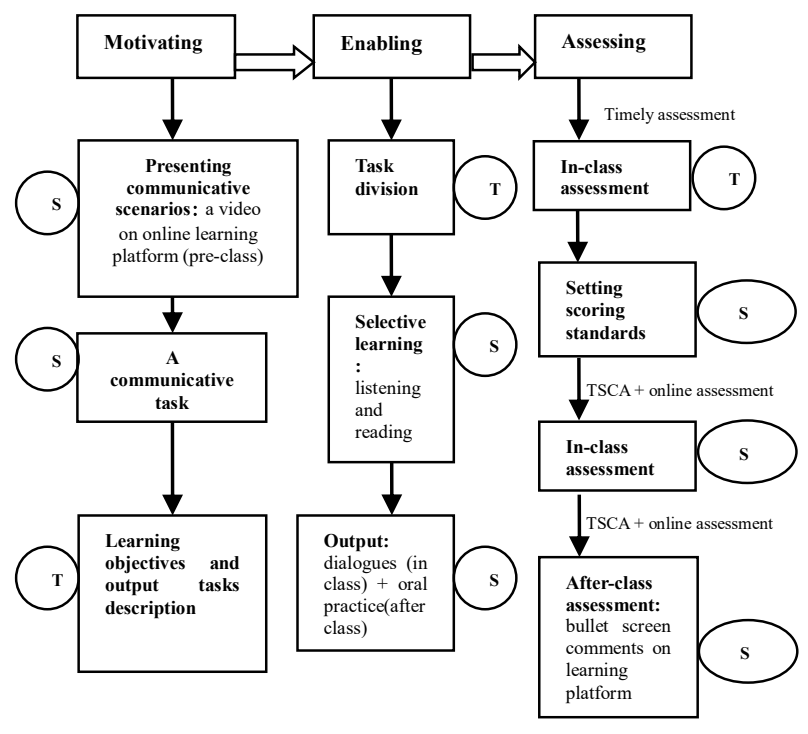

Figure 2: Teaching Process Based on POA and BL

(S stands for students and $\mathrm{T}$ stands for the teacher)

(1) Motivating. In this phase, the communicative scenarios, an English video about "Asking and Directing the Way", was presented to the students through online learning platform before class. Through the video, the students could learn something about how to ask for directions and give directions. Then in class, a map was showed to them and they were encouraged to complete the oral productive task - asking for and giving directions according to the map. This communicative task is closely related to students' lives and is pretty useful in their daily lives. The purpose of this procedure was to make the students realize their deficiencies of language competence and identify their weaknesses in the completion of the task, so as to stimulate their intrinsic motivation of learning. When the students' enthusiasm for learning was aroused, the teacher presented the learning objectives and the output tasks of this unit to the students. The overall learning objective was divided into two aspects: communicative objective and language learning objective. The communicative objective was to enable the students to learn how to ask and direct the way in real life. And the language learning objective was to make them master the vocabularies, phrases, sentence patterns, and logical organization which were related to tasks completion. And the output tasks included the in-class dialogues and after-class oral practice about asking and directing the way.
(2) Enabling. In the first step of the enabling phase, in order to reduce the difficulty of the implementation of the task, the teacher divided the ultimate task into two sub-tasks: in-class dialogues and after-class oral practice. And in-class dialogues includes self-edited dialogue based on the map and random dialogue in real scenarios which arranged by the teacher and TAs in the classroom before class. The aim of these tasks were to make the students master how to ask for and give directions in real scenarios. After the task division, the teacher gave full play to the role of scaffolding, guiding students to group and study input materials selectively. 24 students were divided into 12 groups, each with 2 students. Each group would make a dialogue about asking and directing the way according to a map designed by the teacher. And the input material were three listening materials in unit 6 . The first material was a "True or False" exercise by listening to the speaker giving directions to different places. The second material was "Look at the map and trace the routes" exercise by hearing some short conversations about giving directions. And the third material was "Complete the directions on the map" exercise by listening to two conversations about giving directions. These selected input materials ranged from easy to difficult in order to gradually improve students' abilities of reading maps, tracing route and giving directions and enhance their perception of vocabulary, phrases and sentence patterns about asking and directing the way. After each piece of listening material, the teacher gave her 
guidance by leading the students to summarize the methods of reading the map, tracing routes and giving directions. And then the second and third materials and the map that would be used in the output tasks were uploaded to the class WeChat group and students were instructed to grasp vocabularies, phrases and sentence patterns in these materials in groups and to make a dialogue according to the map. Two or three groups were asked to show their dialogues. The teacher corrected some mistakes and gave some advices for the dialogues. And at last, each group of students was asked to give a random dialogue in real scenarios of the classroom which was arranged according to the map they used in previous task. After class, each group of students should complete oral practice of asking for and giving directions in real scenarios they chose, record it and upload to the online learning platform of our college. This phase emphasizes on the practical arrangements for the productive subtasks, including the selection, transformation of input materials, and the design of the output driven activities. In addition, $\mathrm{BL}$ is also applied in the implementation and completion of the activities to make classroom teaching more efficient and save time in class.

(3) Assessing. In this phase, the timely assessment, TSCA (Teacher Student Collaborative Assessment) and online assessment were combined to evaluate the output tasks in class and after class. The assessment of output tasks in class: after selective learning of the materials about directions in groups and several groups showed their dialogues, the teacher gave timely assessment to point out their merits and demerits. The teacher took these dialogues as typical samples to jointly develop scoring standards with students on the next two output tasks. After each group did a random dialogue in real scenarios of the classroom, the other students gave their assessment in the class WeChat group and the teacher summarized the comments to help students make further improvements when completing the after-school tasks. The assessment of the oral practice after class: Students should send bullet screen comments to conduct selfevaluation and mutual evaluation after the videos of their after-class output task were uploaded to the online learning platform. And then the teacher would give a check and a summary of these comments and their videos would be scored on the online platform, too. In this way, the students could learn a lot and make some further improvements based on the comments and correction.

\subsubsection{Teaching procedure in control class}

The control class adopted the traditional teaching model of "input-output", and followed the regular teaching process of English Visual-audio-oral Course. The first step was to introduce the topic of the unit by presenting a map and explaining how to read the map Second, the teacher gave an explanation of the key words and expressions. Third, students did listening exercises according to the textbook arrangement. Fourth, the teacher asked students to complete the oral output task in groups in the classroom, that is, to make a dialogue about asking and directing the way. And then the teacher gave evaluation for the dialogues. Finally, students should complete the same after-class output task as the experimental class, and upload the video to the online platform for scoring.

\subsection{Research Results and Analysis}

\subsubsection{Experimental process record and results analysis}

The teaching of experimental class and control class were both videotaped and made into video files as the analysis samples of the experiment. After that, the length of teacher's classroom teaching time and students' listening and speaking time, the students' participation rate in classroom and online learning, and the pass rate of output tasks were calculated in both experimental class and control class. The listening time in experimental class includes the listening time in class and the time of watching video before class and the time of evaluating the other students' output tasks after class on the online platform. And the speaking time of the two classes consists of the speaking time in class and speaking time of the oral practice after class. The random dialogues in real scenarios of the classroom were chosen to be the inclass dialogue materials of the experimental group. And the listening and speaking abilities of the students in experimental class and control class before experiment were basically the same, which ensures the reliability and validity of experimental results. The data collection and comparison are as Table 1 shows: 
Table 1. Data Comparison of English Visual-audio-oral Course

\begin{tabular}{|c|l|l|l|l|l|l|c|c|}
\hline Items & $\begin{array}{l}\text { Classroom } \\
\text { teaching } \\
\text { time } \\
\text { (minute) }\end{array}$ & $\begin{array}{l}\text { Listening } \\
\text { Time in } \\
\text { class } \\
\text { (minute) }\end{array}$ & $\begin{array}{l}\text { Listening } \\
\text { Time on } \\
\text { the } \\
\text { online } \\
\text { platform } \\
\text { (minute) }\end{array}$ & $\begin{array}{l}\text { Speaking } \\
\text { Time } \\
\text { (minute) }\end{array}$ & $\begin{array}{l}\text { Participation } \\
\text { rate in } \\
\text { classroom }\end{array}$ & $\begin{array}{l}\text { Participation } \\
\text { rate of } \\
\text { online } \\
\text { learning }\end{array}$ & $\begin{array}{l}\text { Passing rate of the } \\
\text { output tasks }\end{array}$ \\
\cline { 3 - 8 } & $\begin{array}{l}\text { In-class } \\
\text { dialogue }\end{array}$ & $\begin{array}{c}\text { After- } \\
\text { class } \\
\text { oral } \\
\text { practice }\end{array}$ \\
\hline $\begin{array}{c}\text { Control class } \\
\text { class } \\
\text { clamental }\end{array}$ & 18 & 34 & 0 & 44 & $59 \%$ & $0 \%$ & $39 \%$ & $51 \%$ \\
\hline
\end{tabular}

It can be seen from the above table: (1) although this course mainly focuses on students' listening and speaking training, the classroom teaching time of experimental class is still shorter than that of control class; (2) the

total listening and speaking time of the experimental class is longer than that of the control class; (3) the participation rate in classroom and on the online learning especially, is much higher in experimental class; (4) experimental class also has a higher pass rate of both inclass and after-class output tasks; (5) comparing the pass rates of in-class and after-class output tasks, students in experimental class have made greater progress in the after-class task after TSCA.

These data indicate that the student-centered, learning-using integrated teaching principles based on POA can improve the quality of students' language output to a greater extent, which is proved by the higher passing rate of the output tasks in experimental class. And the longer listening and speaking time and much higher participation rate of online learning in experimental class apparently thanks to BL's extension of time and space in classroom. Besides, the reason why the students in the experimental class made greater progress in after-class output task is that the participation of students in the assessment allows students to see the good and weak points of their own dialogues and others' dialogues. All the above suggest that the new teaching mode is superior to the traditional teaching mode.

\subsubsection{Questionnaire survey results analysis}

After the teaching experiment, two teachers in the research team used questionnaires to timely obtain the overall feedback on the teaching of this unit from the two groups of students. There are fifteen questions in the questionnaire, twelve of which are multiple-choice questions and three are free-response questions. The multiple-choice questions involve three aspects: students' satisfaction with the teaching of this unit, the improvement of relevant abilities in learning this unit and the attitudes towards the teaching model used in each class. And the free-response questions are about the students' progress and the problems encountered in the learning process of this unit and the suggestions for the course teaching.

Regarding the satisfaction with the teaching of this unit, only 1 student expressed "not satisfied", 6 students expressed "fair", and the remaining 17 students expressed "satisfied" or "very satisfied" in experimental class, while the control class had 3 students said "not satisfied", 10 students said "fair", and the remaining 11 students said "satisfied" or "very satisfied". In terms of the improvement of related abilities, $70.8 \%$ of the students in the experimental class thought that their comprehensive ability had been improved, and the students who thought that their independent learning ability and their group cooperation ability had improved account for $75 \%$ and $62.5 \%$ respectively. And the corresponding data in control class were $58.3 \%, 45.8 \%, 54.2 \%$. As for the attitudes towards the teaching model of this unit, $79.2 \%$ of the students in the experimental class wanted more classroom design based on POA and BL, so that they could apply the knowledge they had learned in actual communication. And $33.3 \%$ of the students in control class believed that the listening or speaking activities and exercises designed by the teacher in the classroom were not very helpful to their actual oral English expression.

And from the results of the free-response questions, students in experimental class thought that this flexible and interesting teaching model stimulated their enthusiasm and creativity for learning, making them actively participate in learning and evaluation activities. Besides, it improved their abilities in many aspects, such as listening and especially speaking abilities, abilities of critical thinking, autonomous learning and cooperation and the ability to apply knowledge in real situations etc. And for each learning step, they felt that: (1) being asked to direct the way according to a map at the beginning of the class, they could realize the difficulty of the task and be more motivated for further study; (2) selective learning under the guidance of the teacher and output tasks completion in a step-by-step way made them have a better understanding of the learning objectives and processes, and allowed them to use the knowledge they just learned to the tasks immediately; (3) TSCA made them feel more involved in watching and evaluating the output tasks of other groups, from which they could practice their 
listening skills, learn lessons from others and enhance their critical thinking abilities. However, they also pointed out some drawbacks of this teaching model and some obstacles in the learning process. For example, some students with relatively weak English listening foundation could not understand the listening materials thoroughly because of the short listening time in class and they also couldn't participate in the assessment. And it is too time-consuming for all students to present real-world dialogues in class. What's more, some students said that they didn't have enough time to evaluate other groups' tasks after class due to the heavy burden of schoolwork. And they suggested that the listening materials could be uploaded to the online platform before class to practice listening more. They wanted more activities in class, but the classroom efficiency should be paid attention to.

The students in control class mentioned that this traditional teaching model greatly improved their listening skills, but other abilities were not well developed, including the abilities of oral expression, independent learning and so on; the overall participation of students was not very high, and learning was relatively passive; the listening training was not well-targeted, which led to some confusion when editing dialogues; and classroom teaching and learning was a little bit boring. They recommended to design more interesting oral activities, make input materials be more targeted and enhance students' participation in activities through teaching design.

\subsubsection{Teaching logs analysis}

When implementing their own teaching design in their respective classes, the teacher of experimental class and the teacher of control class observed each other's teaching process, and formed teaching reflections in their teaching logs.

After comparing the teaching process of the two classes, the teacher of the control class recorded six teaching deficiencies in control class in her teaching log: (1) The control class only had classroom teaching and no online learning; (2) It had simple lead-in process rather than "output-driven" process; (3) There was no "selective learning" and no consideration of the relevance of input materials and output tasks in the teaching design; (4) Explanations for vocabularies and expressions were given, which didn't involve students' autonomous learning; (5) It had no TSCA and online assessment, but only the traditional teacher evaluation and the machine scoring of the oral online teaching platform; (6) There was no cyclical process of continuous practice, evaluation and improvement.

Both two teachers spoke highly of the new teaching mode of POA combined with BL. And the teacher of experimental class experienced the vitality and efficiency brought by the new teaching mode. It made students more willing to participate in learning and assessments, stimulating their creativity and enhancing their abilities of independent learning, cooperative learning and language application.

In the motivating phase, an audio-visual material was presented on online learning platform to lead in the topic of the unit, and then an oral task was assigned at the beginning of class to create students' thirst for further study. This design could greatly stimulate their desire and enthusiasm for learning by making them realize their limitations. In the enabling phase, practical language knowledge, pragmatic knowledge and communication strategies were mastered by students through selective learning and completion of output tasks. The selective learning materials chosen by the teacher enabled students to grasp vocabularies, phrases and sentence patterns which were required in the output tasks. And the output tasks were rich in content, clear in purpose, and completed in real scenarios, highlighting the "learningusing integration" principle. The teaching processes were both challenging and full of fun, which significantly improved the teaching and learning effect. Besides, both selective learning and completion of output tasks were based on groups, which was beneficial to enhance students' autonomous learning ability and cooperative ability. In the assessment phase, there were three rounds of evaluation. The first round of teachers' timely assessment of the dialogues provided students with evaluation criteria. The second and third rounds both included students' comments and the teacher' summarizations which could help students discover the merits and demerits of their own and others and learn from each other during the evaluation process. Thus each round enabled students to get further improvements. Students were in a dynamic cycle of "motivatingenabling-assessing", which greatly improved the learning effect. In addition, students were more willing to take part in TSCA and online assessment which are funny and break the limitation of time and space. And their enthusiasm in learning and improving were greatly stimulated by the combination of timely assessment, TSCA and online assessment.

The new teaching mode, POA combined with BL, can develop the learning potential of high-quality English learners among students. Nevertheless, some students with relatively low English level were not capable of completing the output tasks and assessments. For them, although there was time for selective learning in the class, the usage of vocabulary, phrases and sentence patterns could not be absorbed thoroughly and immediately to be used flexibly in completing oral tasks. And they could not fully grasp the meaning of the dialogues of other groups, so they couldn't give effective evaluation. This requires teachers use different teaching strategies according to the differences of students' English level. What's more, since every group was required to give a random dialogue in real scenarios of classroom and make assessments in 
class, it took too much time and each group only had a few minutes to practice, which led to low learning efficiency.

\section{CONCLUSION}

\subsection{Superiority of $P O A$ and $B L$}

The new teaching mode combining POA and BL is a big revolution of the traditional "input-output" English teaching model. Being production-oriented, POA adopts a three-step of teaching process of "motivating-enablingevaluating", integrates teaching concepts of "learning centered", "learning-using integrated" and "wholeperson education" throughout the teaching process, and advocates "teacher-led and student-oriented" Principle.

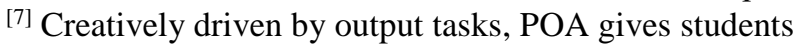
many opportunities to use English in real communicative scenarios, and enable them to quickly apply language knowledge and communication skills acquired through selective learning to output tasks, which greatly improves the efficiency of language learning and language output. The comparison of the pass rates of the two groups of students' output tasks shows that the new teaching mode has a certain positive effect on improving the students' English oral proficiency. Compared with the traditional teaching model, POA can create realistic pragmatic opportunities in the communicative context, and stimulate students' enthusiasm and creativity to complete the output task to a greater extent. Besides, learning and task completion are carried out in groups, which helps students enhance their cooperative ability and team spirit. For the evaluation of the output tasks, TSCA and online assessment make students learn from one another, cultivate students' critical thinking ability and make evaluation process interesting. This solves the problem of the traditional teacher assessment, that is, the students' lack of the sense of participation makes them unwilling to listen carefully to the output of other groups and the teacher's comments.

Combining the advantages of offline learning with online learning, BL make teaching and learning more convenient, flexible and efficient. It expands classroom resources and learning time and space. The online learning resources composed of sounds, words, and images can better meet the needs of students' individualized learning and autonomous learning. And some activities are arranged before or after class through the online learning platform to save time for classroom teaching and cultivate students' ability of independent learning and cooperative learning. In addition, diverse and interesting ways of online mutual evaluation make students more willing to take part in such activities and learn from each other while evaluating. What's more, BL enables teachers to change from traditional knowledge interpreters, transmitters, and indoctrinators to organizers, participants, instructors, and facilitators of students' learning and the emphasis of teaching is shifted from "transmitting knowledge" to "instructing students to learn independently".

\subsection{Difficulties and Challenges}

After the teaching experiment, the author found that some difficulties and challenges still exist in the effective implementation of the new teaching mode in the English Visual-audio-oral Course.

(1) Since the application of this teaching mode is a new attempt in English Visual-audio-oral Course teaching in our college, there is few mature teaching cases to learn from. Despite the theoretical frameworks and measures for the implementation of the teaching processes, it is challenging, time-consuming and laborious for teaching design. To solve this problem, the teachers who teach this course should constantly study the teaching theories and teaching strategies together, design the teaching processes collectively, and integrate theories with practice so as to make the new teaching mode be thoroughly implemented.

(2) POA requires input materials to be connected with the real life of students, but some materials in textbooks do not meet or fully meet this requirement. Besides, teaching materials should be selected based on students' English level in order to make learning more effective. Therefore, teachers need to select some extracurricular materials and control the difficulty of selected materials according to the English level of students, which require teachers to have extensive knowledge and rich experience in mastering the level of students.

(3) Sometimes, it is hard to control the difficulty level of the output tasks. When designing subtasks, teachers should take into consideration the uneven English language ability and cognitive level of students and try to balance the difficulty of subtasks, so as to achieve the two major teaching goals of "language" and "communication".

(4) Since BL requires teachers and students to be familiar with the operation of the online learning platform, it needs technical training support from the school and the joint efforts of teachers and students. In addition, if more and more courses choose to arrange preclass or after-class activities on the online learning platform, students' spare time may be heavily occupied, which may lead to students' perfunctory completion of tasks that will inevitably affect their learning effect.

(5) Compared with traditional teaching methods, whether the new teaching mode is more suitable for students with weak English foundation in promoting their English skills remains to be tested in the future teaching practice.

All in all, in spite of some difficulties and challenges, the new teaching mode, the combination of POA and BL, 
is still worthwhile for the practical teaching of college English teachers. And further exploration of POA and BL is necessary in order to find an effective way to change the traditional way of English Visual-audio-oral Course teaching in colleges and improve students' comprehensive application ability of English.

\section{AUTHORS' CONTRIBUTIONS}

On the basis of studying relevant theories, Li Naiqian designed the comparative teaching experiment and student questionnaires. She and another team member performed the experiment in their English Visual-audiooral classes and conducted the questionnaire survey in the two classes and compiled teaching logs to form teaching reflections. In addition, Li Naiqian collected the output results and related data of the experimental class and the control class, did a comparative analysis of the data, and wrote and modified the thesis. Associate Prof. Wu Yafei gave valuable suggestions on the revision of the paper.

\section{ACKNOWLEDGMENT}

I would like to express my sincere gratitude to Associate Prof. Wu Yafei, my colleague who, with extraordinary patience and consistent encouragement, gave me great help by providing me with necessary materials, advice of great value and inspiration of new ideas.

Found Project: Research on BL Teaching Model Based on POA Theory, Guangdong Province Educational Science "13th Five-Year Plan" Project (Project Number: 2018GXJK265).

\section{REFERENCES}

[1] Wen Qiufang, Developing a Theoretical System of the Production-oriented Approach in Language Teaching, Foreign Language Teaching and Research, 2015, (4).

[2] S. Kranshen, The Input Hypothesis: Issues and Implications, London: Longman, 1985.

[3] M. Swain, Three Functions of Output in Second Language Learning, In G. Cook \& B. Seidlhofer (Eds.), Principles and Practice in Applied Linguistics: Studies in Honor of H.G. Widdowson, Oxford: OUP,1995, pp. 125-144.

[4] Wen Qiufang, Chinese Features Displayed in the Production-oriented Approach, Modern Foreign Languages, 2017, (3).

[5] Huang Ronghuai, Zhou Yueliang, Wangying, Theory and Practice of Blended Learning, Beijing: Higher Education Press, 2006.

[6] Wen Qiufang, Developing a Theoretical System of the Production-oriented Approach in Language Teaching, Foreign Language Teaching and Research, 2015, (4), pp. 547558. 